\title{
A survey on student pharmacists' knowledge, attitude and perceptions about drug and poison information elective rotation in Saudi Arabia
}

\author{
Otilia J F Banji (D), Shamna Machanchery, David Banji , Ahmed A Albarraq, Hafiz A Makeen \\ Department of Clinical Pharmacy, College of Pharmacy, Jazan University, Saudi Arabia
}

\author{
Keywords \\ Drug and Poison Information \\ Knowledge \\ Attitude \\ Perception \\ Pharm.D. Interns
}

\section{Correspondence \\ Dr. Otilia J F Banji \\ Professor, \\ Department of Clinical \\ Pharmacy, \\ Jazan University \\ otiliabanji@gmail.com}

\begin{abstract}
Background: Drug and poison information (DPI) elective rotation develops interns into drug information experts, educators, and policymakers. DPI is an important pharmaceutical service built on technical skills, knowledge and expertise. Aim: A pre- and post-rotation survey to assess the current knowledge, attitude and perceptions of student pharmacists about DPI rotation. Methods: Three cohorts of student pharmacists responded to the survey, which was composed of closed- and open-ended questions. Descriptive statistics, McNemar's test, and Chi-square test were utilised for data analysis. Results: Knowledge of primary resources increased from $37.2 \%$ to $85.6 \%$ at the end of the rotation. In the beginning, only $13.8 \%$ were aware of Pharmacy and Therapeutic committee related activities, and $15.9 \%$ considered identification adverse drug reactions as auxiliary responsibilities. However, the proportion increased to $82 \%$ and $83.5 \%$ by the end of the rotation. Both at the beginning and the end, student pharmacists felt the training was essential to appraise literature. Twice the number of respondents expressed that there were job opportunities in the DPI centre post-rotation compared with the pre-rotation response $(p<0.001)$. The perception of responding to queries at their own pace was significantly reversed post-rotation $(p<0.001)$. A significant association was found between opportunities in DPI centre and motivation to choose this rotation $(p<0.05)$. Also, knowledge of primary resources with previous research was significantly associated $(p<0.05)$. Conclusion: Interventions such as journal club, guest lectures and visit to the DPI centre significantly improved the knowledge, attitude and perceptions of student pharmacists towards this DPI rotation.
\end{abstract}

\section{Introduction}

The Doctor of Pharmacy (Pharm.D.) programme is a six-year, full-time professional degree course conducted throughout the Kingdom of Saudi Arabia (Ahmed Al-jedai, 2016). The programme equips student pharmacists with clinical, biomedical and scientific knowledge and skills. The coursework is covered in five years (ten semesters), and after its completion, student pharmacists go through one year of advanced pharmacy practice experience (APPE). During the ninth semester of the academic phase, student pharmacists are introduced to the concepts of drug information and utilisation. Following this, in the tenth semester, they undertake evidence-based medicine, and both these courses are delivered as theory subjects (Ahmed Al-jedai, 2016).

During the APPE, student pharmacists are offered six core rotations and four elective rotations to develop their practice skills and promote patient care. Student pharmacists can select from electives such as drug and poison information (DPI), total parenteral nutrition, inventory control, and chronic diseases. The rotation allotment is done based on their preferences, availability of slots and availability of preceptors. 
During the DPI rotation, student pharmacists are challenged with practical problems related to drugs and poisons, taught to critically appraise medical information, and trained to reciprocate explicitly to queries. Hence the purpose of this rotation is to strengthen the knowledge learned during the educational phase and prepare them to face multiple tasks that the pharmacist needs to perform in the DPI centre.

DPI is an essential pharmaceutical service providing factual information to healthcare professionals (Cafege, 1989). It serves as a vital source of information to clinicians during emergencies as they may require evidence-based therapeutic recommendations within a short time frame (Strobach et al., 2015; Alamri et al., 2017). The queries could be related to the pharmacokinetic profile, drug interactions, compatibility issues, and the possibility of intolerance. Apart from the clinicians, patients and consumers might seek medical information. To impart explicit details, the DPI centre pharmacist should be knowledgeable, should be acquainted with drug information resources, and have the skill to retrieve, validate, and provide information within the stipulated time frame. Also, DPI pharmacists carry out other responsibilities such as preparing public education material, patient information leaflets, adverse drug reaction (ADR) monitoring, Pharmacy and Therapeutics related activities, information on abusive substances, toxico- vigilance, developing clinical decision support tools, and formulating drug policies (Walton \& Knodel, 1983; Ruppelt \& Vann, 2001; WHO, 2004; Rahmner et al., 2017). Hence, student pharmacists need technical training as well as skills in time management, leadership and organisation to perform the multifaceted tasks of the DPI pharmacist.

Table I: Responses of student pharmacists to a preliminary survey on elective rotations

\begin{tabular}{lc}
\hline Characteristics & Frequency (\%) \\
\hline Gender & $119(44.90)$ \\
Females & $146(55.09)$ \\
Males & \\
Elective rotation preferences & $141(53.20)$ \\
Chronic diseases & $65(24.52)$ \\
Inventory control & $59(22.26)$ \\
Drug and poison information & \\
Reasons quoted about DPI & $93(35.09)$ \\
No patient contact & $64(24.15)$ \\
Limited options & $108(40.75)$ \\
\hline
\end{tabular}

To assess student pharmacists' preferences for core and elective rotations, the authors conducted a preliminary survey a month before completing their academic coursework. They found that only $22.2 \%$ of the student pharmacists preferred the DPI rotation over the other electives (Table I). As DPI is a crucial elective rotation, student pharmacists need to foster interest, competence, and confidence to undertake this rotation. Thus, the authors assessed the knowledge, attitude, and perceptions of student pharmacists towards DPI elective rotation both at the beginning and at the end of the rotation.

\section{Design \\ Ethics approval}

The Institutional Review Board, College of Pharmacy, Kingdom of Saudi Arabia, approved the proposal bearing number 3812/222/1438 dated 23rd November, 2016.

The study was a descriptive pre-post survey carried out on student pharmacists during their APPE experience. Two hundred and eighty-seven student pharmacists from three cohorts undertook training locally from January 2017 to August 2018. Out of these, 238 student pharmacists were allotted the DPI rotation, with the numbers differing for each cohort. One hundred and forty-eight respondents consented to participate in the pre-rotation survey. The questionnaire was structured based on a literature search (Asiri et al., 2007; Wojas \& Graham, 2009; Churi et al., 2013; Ghaibi, Ipema, \& Gabay, 2015; Khaliq \& Sayed, 2016; WHO, 2020) and read by two experienced preceptors. As two questions on knowledge and two items from the perception section were ambiguous, they were deleted. The questionnaire had three modules to evaluate the current knowledge, attitude and perceptions towards the DPI rotation, containing both open- and closed-ended questions. Also, the gender of the respondents and their prior involvement in medical research were recorded. The student pharmacists then went through one-month of DPI rotation training.

Unlike the other rotations, the DPI rotation is conducted on the University campus and monitored by experienced preceptors. The rotation begins with an orientation to provide insight on the DPI rotation. Student pharmacists are provided with case scenarios and advised to search and compute their responses in the best possible manner. The preceptor then provides feedback to the response submitted through face-to-face interaction with the student pharmacists and clarifies their doubts, if any. Apart from case scenarios, the student pharmacists also 
undertake journal club presentations, prepare monographs, creates patient information leaflets, and public education material.

After completing the DPI rotation, a follow-up survey was conducted, and one hundred and thirty-nine respondents participated in the post-rotation study.

\section{Data analysis}

Data were entered into Microsoft Excel and analysed using version 23.0 SPSS for Windows (SPSS Inc., Chicago, IL). Frequencies were computed for all variables. McNemar's test (Verhoef et al., 2013) was used to assess the differences in pre-post responses given by the student pharmacists. Also, the level of association between the knowledge of information resources with prior research undertaken, motivation to choose the rotation, and its association with opportunities in the DPI were assessed by the Chi-square test. The level of significance was set at $p<0.05$.

\section{Evaluation and assessment}

In the pre-rotation survey, of a total of 148 randomly selected student pharmacists, three questionnaires were rejected as they contained several questions unanswered, giving a response rate of $97.97 \%$. In the post-rotation survey, 139 student pharmacists responded, giving a response rate of $93.91 \%$. Among the respondents, $47.6 \%$ were females, and $52.4 \%$ were males. In total, $40.7 \%$ of student pharmacists undertook some form of prior research, with $4.1 \%$ participating in the preparation of reviews, $11 \%$ in original research, and $25.5 \%$ working in group research (Table II).

Table II: Baseline characteristics of student pharmacists opting the drug and poison information centre rotation

\begin{tabular}{lc}
\hline Characteristics & Frequency (\%) \\
\hline Gender (pre-rotation) & $69(47.6)$ \\
Females & $76(52.4)$ \\
Males & \\
\hline Gender (post-rotation) & $67(48.20)$ \\
Females & $72(51.79)$ \\
Males & \\
\hline Prior research undertaken & $59(40.7)$ \\
Yes & $86(59.3)$ \\
No & \\
\hline Type of research undertaken (N=59) & $6(10.2)$ \\
Reviews & $16(27.1)$ \\
Original research & $37(62.7)$ \\
Group research & \\
\hline
\end{tabular}

A remarkable change was observed in identifying the resources needed in the DPI between the pre- and post-rotation survey. Nearly $72 \%$ of student pharmacists exhibited awareness of the role and responsibilities of the DPI pharmacist in the post-rotation study (Table III). Also, over one-half of the respondents were aware of all the ADR reporting systems contrary to their lack of knowledge at the beginning of the rotation (Table III).

Table III: Knowledge of student pharmacists before and at the end of the drug and poison information centre rotation

\begin{tabular}{lcc}
\hline Knowledge of DPI & $\begin{array}{c}\text { Pre-rotation } \\
\mathbf{n}(\%)\end{array}$ & $\begin{array}{c}\text { Post-rotation } \\
\mathbf{n}(\%)\end{array}$ \\
\hline Information resources in DPI & $\mathbf{( N = 1 4 5 )}$ & $\mathbf{N}=139$ \\
Micromedex & $65(44.8)$ & $13(9.4)$ \\
Lexicomp & $42(28.9)$ & $13(9.4)$ \\
Clinical Pharmacology/ & $18(12.4)$ & $5(3.6)$ \\
Martindale & & \\
Journals & $12(8.2)$ & $7(5.0)$ \\
All & $8(5.5)$ & $101(72.7)$ \\
\hline Role of DPI pharmacists & $\mathbf{( N = 1 4 2 )}$ & $\mathbf{N}=137$ \\
Developing drug policies & $36(24.8)$ & $18(13.1)$ \\
Prepare dosing protocols & $17(11.7)$ & $9(6.6)$ \\
Conduct educational & $65(44.8)$ & $32(23.4)$ \\
programs & & \\
Carry out economic analysis & $24(16.5)$ & $7(5.1)$ \\
All & - & $71(51.8)$ \\
Adverse drug reporting systems & $\mathbf{( N = 1 4 5 )}$ & $\mathbf{N}=139$ \\
Medwatch & $64(44.1)$ & $20(14.4)$ \\
Yellow card & $28(19.3)$ & $14(10.1)$ \\
Both & $40(27.5)$ & $13(9.4)$ \\
Saudi ADERS & $13(8.9)$ & $17(12.2)$ \\
All & - & $75(54)$ \\
\hline
\end{tabular}

The knowledge of tertiary information resources such as Micromedex, Lexicomp, textbooks, and compendia did not differ before and after the rotation; however, awareness of primary information resources such as original research publications in journals improved from $37.2 \%$ to $85.6 \%$ by the end of the rotation (Table IV). Only $15.9 \%$ and $13.8 \%$ student pharmacists in the pre-rotation survey perceived that the DPI pharmacists are involved in identifying $A D R$, and participating in Pharmacy and Therapeutic committee related activities; however, during the post-rotation survey, a significant increase in response to $82 \%$ and $83.5 \%,(p<0.001)$ respectively, was observed (Table IV). 
Table IV: Student pharmacists awareness at the beginning and at the end of the drug and poison information centre rotation

\begin{tabular}{|c|c|c|c|c|c|}
\hline \multirow[t]{2}{*}{ Knowledge of DPI } & \multicolumn{2}{|c|}{$\begin{array}{c}\text { Pre-rotation } \\
\mathbf{N}(\%)\end{array}$} & \multicolumn{2}{|c|}{$\begin{array}{c}\text { Post-rotation } \\
\text { N (\%) }\end{array}$} & \multirow[t]{2}{*}{$\begin{array}{c}p- \\
\text { value }\end{array}$} \\
\hline & Yes & No & Yes & No & \\
\hline \multicolumn{6}{|c|}{ Knowledge of information sources } \\
\hline & \multicolumn{2}{|c|}{$N=145$} & \multicolumn{2}{|c|}{$N=139$} & \\
\hline Primary & $\begin{array}{c}54 \\
(37.2)\end{array}$ & $\begin{array}{c}91 \\
(62.8)\end{array}$ & $\begin{array}{c}119 \\
(85.6)\end{array}$ & $\begin{array}{c}20 \\
(14.4)\end{array}$ & $0.001 *$ \\
\hline Secondary & $\begin{array}{c}66 \\
(45.5)\end{array}$ & $\begin{array}{c}79 \\
(54.5)\end{array}$ & $\begin{array}{c}111 \\
(76.9)\end{array}$ & $\begin{array}{c}28 \\
(20.1)\end{array}$ & $0.001 *$ \\
\hline Tertiary & $\begin{array}{c}137 \\
(94.5)\end{array}$ & $\begin{array}{c}8 \\
(5.5)\end{array}$ & $\begin{array}{c}138 \\
(99.3)\end{array}$ & $\begin{array}{c}1 \\
(0.7)\end{array}$ & $0.031^{*}$ \\
\hline
\end{tabular}

Important tasks that pharmacists have in DPI

\begin{tabular}{|c|c|c|c|c|c|}
\hline $\begin{array}{l}\text { Information } \\
\text { provider }\end{array}$ & $\begin{array}{c}105 \\
(72.4)\end{array}$ & $40(27.6)$ & $\begin{array}{c}123 \\
(88.5)\end{array}$ & $\begin{array}{c}16 \\
(11.5)\end{array}$ & $0.001 *$ \\
\hline $\begin{array}{l}\text { Identifying } \\
\text { ADR/Drug } \\
\text { interactions }\end{array}$ & $\begin{array}{c}23 \\
(15.9)\end{array}$ & $\begin{array}{c}122 \\
(84.1)\end{array}$ & $\begin{array}{l}114 \\
(82)\end{array}$ & $\begin{array}{c}25 \\
(18)\end{array}$ & $0.001 *$ \\
\hline $\begin{array}{l}\text { Participating in } \\
\text { P\&T activities/ } \\
\text { guidelines }\end{array}$ & $\begin{array}{c}20 \\
(13.8)\end{array}$ & $\begin{array}{c}125 \\
(86.2)\end{array}$ & $\begin{array}{c}116 \\
(83.5)\end{array}$ & $\begin{array}{c}23 \\
(16.5)\end{array}$ & $0.001 *$ \\
\hline
\end{tabular}

DPI: Drug and poison information; ${ }^{*} p<0.05$ considered statistically significant; ADR Adverse drug reactions; P\&T: Pharmacy and Therapeutic.

The pre- and post-rotation survey yielded identical responses with regards to the attitude of the student pharmacists meeting their preceptor, critically appraising information, and the usefulness of the academic programme. At the end of the rotation, nearly twice the proportion (71.9\%) of student pharmacists believed there were job opportunities in this sector. The confidence to prepare patient education material was relatively higher at the end of the rotation (Table V).

The majority of the student pharmacists (84.1\%) perceived that they have to respond to queries at a fast pace by the end of the rotation. Student pharmacists had lower confidence in providing drug information; however, this improved by the end of the rotation $(p<0.001)$. Also, a significant difference in pre- and post-response was reported among student pharmacists as most of them (89.9\%) visited the DPI at the end of the rotation $(p<0.001)$. The perception of the use of medical jargon did not change before and at the end of the rotation. Student pharmacists also showed an increase in their perception of referring others to the DPI (87.1\%) (Table V).

As shown in Table VI, the authors found student pharmacists who researched during their academic phase were more familiar with primary resources $\left[\chi^{2}(1, N=145)\right.$
=4.44, $p=0.038]$. Also, the motivation to choose the rotation was influenced by job opportunities in the DPI $\left[\chi^{2}(3, N=145)=9.92, p=0.019\right]$.

Table V: The attitude and perceptions of student pharmacists towards the drug and poison information centre rotation

\begin{tabular}{|c|c|c|c|c|c|}
\hline \multirow[t]{3}{*}{ Variable } & \multicolumn{2}{|c|}{ Before } & \multirow{2}{*}{\multicolumn{2}{|c|}{$\begin{array}{c}\text { After rotation } \\
\mathbf{N}(\%)\end{array}$}} & \multirow{3}{*}{$\begin{array}{c}p \text { - } \\
\text { value }\end{array}$} \\
\hline & \multirow{2}{*}{$\begin{array}{c}\text { rotation } \\
\text { Yes }\end{array}$} & \multirow{2}{*}{$\begin{array}{c}\mathbf{N}(\%) \\
\text { No }\end{array}$} & & & \\
\hline & & & Yes & No & \\
\hline \multicolumn{6}{|l|}{ Attitude } \\
\hline $\begin{array}{l}\text { Important to meet my } \\
\text { preceptor regularly }\end{array}$ & $\begin{array}{c}120 \\
(82.8)\end{array}$ & $\begin{array}{c}25 \\
(17.2)\end{array}$ & $\begin{array}{c}127 \\
(91.4)\end{array}$ & $\begin{array}{c}12 \\
(8.6)\end{array}$ & $0.008 *$ \\
\hline $\begin{array}{l}\text { Academic programme } \\
\text { will be useful in } \\
\text { understanding drug } \\
\text { therapy related } \\
\text { problems }\end{array}$ & $\begin{array}{c}143 \\
(98.6)\end{array}$ & $\begin{array}{c}2 \\
(1.4)\end{array}$ & $\begin{array}{c}138 \\
(99.3)\end{array}$ & $1(0.7)$ & 1.0 \\
\hline $\begin{array}{l}\text { DPI has many job } \\
\text { opportunities for } \\
\text { pharmacists }\end{array}$ & $\begin{array}{c}51 \\
(35.1)\end{array}$ & $\begin{array}{c}94 \\
(64.8)\end{array}$ & $\begin{array}{c}100 \\
(71.9)\end{array}$ & $\begin{array}{c}39 \\
(28.1)\end{array}$ & $0.001 *$ \\
\hline $\begin{array}{l}\text { DPI training is needed to } \\
\text { improve my ability to } \\
\text { critically appraise } \\
\text { literature }\end{array}$ & $\begin{array}{c}131 \\
(90.3)\end{array}$ & $\begin{array}{c}14 \\
(9.7)\end{array}$ & $\begin{array}{c}128 \\
(92.1)\end{array}$ & $\begin{array}{c}11 \\
(7.9)\end{array}$ & 1.0 \\
\hline $\begin{array}{l}\text { I can prepare patient } \\
\text { education leaflets }\end{array}$ & $\begin{array}{c}23 \\
(15.9)\end{array}$ & $\begin{array}{c}122 \\
(84.1)\end{array}$ & $\begin{array}{c}112 \\
(80.6)\end{array}$ & $\begin{array}{c}27 \\
(19.4)\end{array}$ & $0.001 *$ \\
\hline \multicolumn{6}{|l|}{ Perceptions } \\
\hline $\begin{array}{l}\text { I can take time to } \\
\text { provide a response }\end{array}$ & $\begin{array}{c}122 \\
(84.1)\end{array}$ & $\begin{array}{c}23 \\
(15.9)\end{array}$ & $\begin{array}{c}14 \\
(9.7)\end{array}$ & $\begin{array}{c}125 \\
(89.9)\end{array}$ & $0.001 *$ \\
\hline $\begin{array}{l}\text { Should answers to } \\
\text { questions include } \\
\text { medical jargon }\end{array}$ & $\begin{array}{c}14 \\
(9.7)\end{array}$ & $\begin{array}{c}131 \\
(90.3)\end{array}$ & $\begin{array}{c}3 \\
(2.1)\end{array}$ & $\begin{array}{c}134 \\
(92.4)\end{array}$ & $0.002 *$ \\
\hline $\begin{array}{l}\text { Will refer anyone facing } \\
\text { drug therapy problems } \\
\text { to contact the DPI }\end{array}$ & $\begin{array}{c}95 \\
(65.5)\end{array}$ & $\begin{array}{c}50 \\
(34.5)\end{array}$ & $\begin{array}{c}121 \\
(87.1)\end{array}$ & $\begin{array}{c}18 \\
(12.9)\end{array}$ & $0.001 *$ \\
\hline $\begin{array}{l}\text { Are you confident in } \\
\text { providing drug } \\
\text { information at present? }\end{array}$ & $\begin{array}{c}18 \\
(12.4)\end{array}$ & $\begin{array}{c}127 \\
(87.5)\end{array}$ & $\begin{array}{c}126 \\
(90.6)\end{array}$ & $\begin{array}{c}13 \\
(9.4)\end{array}$ & $0.001 *$ \\
\hline $\begin{array}{l}\text { Have you visited the DPI } \\
\text { in your locality? }\end{array}$ & $\begin{array}{c}8 \\
(5.59)\end{array}$ & $\begin{array}{c}135 \\
(94.4)\end{array}$ & $\begin{array}{c}125 \\
(89.9)\end{array}$ & $\begin{array}{c}14 \\
(10.1)\end{array}$ & $0.001^{*}$ \\
\hline
\end{tabular}

DPI: Drug and poison information; ${ }^{*} p<0.05$ considered statistically significant.

Table VI: Association between factors with relation to the drug and poison information centre rotation

\begin{tabular}{lcc}
\hline Variable & $\chi^{2}$ (df) & $p$ \\
\hline $\begin{array}{l}\text { Prior research* Knowledge of primary } \\
\text { information sources }\end{array}$ & $4.44(1)$ & $0.038^{*}$ \\
$\begin{array}{l}\text { Job opportunities in DPI* Motivation to } \\
\text { choose this rotation }\end{array}$ & $9.92(3)$ & $0.019 *$
\end{tabular}

DPI: Drug and poison information; ${ }^{*} p<0.05$ considered statistically significant, ADR: Adverse drug reactions 


\section{Discussion}

The study demonstrated significant improvement in the knowledge, attitude and perceptions of student pharmacists towards the DPI rotation at the end of experiential learning.

The DPI Service is primarily set up with the goal of providing drug information (Wojas \& Graham, 2009). Nearly three-fourths of the student pharmacists in the study reinforced this concept that the DPI pharmacist would be mainly involved in providing drug information. However, student pharmacists were less familiar with auxiliary tasks undertaken by the pharmacists in the DPI centre, which significantly improved at the end of the rotation.

Clinicians and the public may seek credible information on drugs and poisons. However, in the case of clinicians, time is a major constraint due to long queues of patients, surgeries and hospital rounds (Hedegaard \& Damkier, 2009; Steel et al., 2014). A well-trained pharmacist can provide accurate information that can aid in the decision-making process (Gelayee, Mekonnen, \& Birarra, 2007). To provide accurate information, student pharmacists should have sound knowledge and skills to search and retrieve information from the right source before giving it to the enquirer. The authors found the majority of the respondents familiar with tertiary information resources, and this response was consistent both at the beginning and at the end of the rotation. Tefera et al. have reported that over $80 \%$ of the answers to queries are done after referring to tertiary information sources (Tefera et al., 2019). Also, a study conducted in Singapore and several other studies has reported the use of tertiary information resources as they are considered succinct and utilised more compared with primary information resources (Ponampalam, Anantharaman, 2003; Wong, Ko, \& Sklar, 2009; Almazrou, Ali, \& Alzhrani, 2017). Only a little over one-third knew of primary information resources at the beginning of the rotation. Still, an appreciable change was observed at the end of the rotation, implying that the strategies advocated during the rotation were helpful for the student pharmacists. Primary resources are not a common source of information when handling queries, as reported in a study conducted in Ethiopia (Hedegaard \& Damkier, 2009). However, for more specialised information, primary resources could be beneficial, and students need to be trained to use them effectively.

Familiarity with developing drug policies on medication use and engaging in pharmacoeconomic evaluations was limited. Nonetheless, nearly one-half of the student pharmacists believed that pharmacists could organise continuing education programmes. This agrees with the findings of a study conducted in a teaching hospital in Nepal, wherein, they have reported that DPI pharmacists are engaged in continuing professional development sessions (Shanker et al., 2007). However, at the end of the rotation, nearly three-fourth student pharmacists felt that the DPI pharmacists have a multifaceted role to play.

Less than one-fourth of the student pharmacists selecting the DPI rotation as a personal choice in the pre-rotation survey plausibly due to lack of awareness of the importance of DPI pharmacists. However, nearly one-half were motivated to undertake it following counselling, and almost $18 \%$ opted for this rotation based on their classmate's recommendation. Incidentally, as only $5.5 \%$ of student pharmacists had visited the DPI in their area, they might have had a limited understanding of the varied activities taking place in these centres. As the roles and responsibilities of pharmacists have evolved with time, the authors organised two visits to the DPI centre located in this region. Thus, they gained insight into the changing roles of the DPI pharmacists. Accordingly, their awareness and perceptions changed, as nearly $90 \%$ of them visited the DPI by the end of the rotation.

One-third of the student pharmacists perceived that there were limited job opportunities in this area before the commencement of the rotation. This factor might have deterred them from opting for this rotation. Interestingly, the proportion of student pharmacists perceiving job opportunities doubled by the end of the rotation. Healthcare professionals in Saudi Arabia and the United Arab Emirates are poorly informed of the scope of drug information centres (Abou-Auda, 2008; Gharibyar et al., 2013). Hence, when healthcare sector professionals themselves lack awareness, it is not surprising to obtain a similar response from student pharmacists. A study from Singapore revealed that $41 \%$ of physicians preferred pharmacists as providers of drug information (Tefera et al., 2019). Moreover, in the Kingdom of Saudi Arabia, several National Drug and Poison Information Centres (NDIC) have been operationalised in several hospitals and over 2,500 primary healthcare centres, (Alomi et al., 2016), creating immense job opportunities in this domain.

Astonishingly, the authors also found that only around 9\% of the student pharmacists knew about Saudi Adverse Event Reporting System (ADERS), while nearly one-half of the student pharmacists were aware of adverse drug reporting through Medwatch. However, at the end of the rotation, their awareness of all the ADR reporting systems notably improved. 
During an emergency, providing quality information within a stipulated time could be life-saving (Al Doughan, Alomi, \& Iflaifel, 2019). Still, the pre-rotation survey revealed that $84 \%$ of the student pharmacists felt they could respond at their own pace. This response coincides with the findings of another study wherein, graduating pharmacy students took anywhere between five minutes to one-hour to handle queries indicating that it was not time intensive (Ponampalam \& Anantharaman, 2003). Another study revealed that the time spent responding to queries could also depend on the complexity of the question and the type of information resources searched (Reppe, Spigset, \& Schjøtt, 2010). Incidentally, training substantially changed the perception of student pharmacists' with nearly $90 \%$ perceiving the importance of responding quickly.

Also, a desirable trait of the drug information specialist is to provide information without including complicated medical terms. The authors found the majority of the student pharmacists responding accordingly at the beginning and end of the rotation.

The $40 \%$ of student pharmacists who engaged in research activities during their academic phase possessed significantly better knowledge of primary information resources than student pharmacists who never undertook research.

An essential part of the learning process is to receive constructive criticism and guidance from the preceptor and build a healthy relationship with them (Batool, Muzzamil, \& Qureshi, 2019). Many activities can be performed through preceptor support as they play a significant role in capacity building, provided the student pharmacists regularly interact with them. Over $80 \%$ of student pharmacists desired to receive guidance and feedback from their preceptors to improve their performance. Also, over $90 \%$ of them felt that they need support to appraise medical literature critically.

Also, a little over $60 \%$ of the student pharmacists felt they would recommend family and friends to consult and utilise the services of the DPI before the rotation. A study conducted in Pakistan reported that students and interns showed the least usage of the DPI services (Batool, Muzzamil, \& Qureshi, 2019). A similar finding was reported in Ethiopia, wherein respondents did not contact the drug information centre for their needs (Gelayee, Mekonnen, \& Birarra, 2007). Also, Almazrou et al. (2017) have stated the necessity of creating awareness of DIC to promote consultations with DIC pharmacists (Almazrou, Ali, \& Alzhrani, 2017). Hence, it is vital to refer others to the DPI centre, and the proportion of student pharmacists showing confidence in DPI improved after the rotation.

Based on the information collected before the rotation, the authors encouraged student pharmacists to participate in journal club sessions and manuscript writing to foster critical thinking and familiarise them with information resources. To complement the current strategy, two visits were organised to the DPI centre, regular guest lectures, seminars, and workshops from experts in toxicology and emergency medicine, to gain insights into the practical approach of addressing drug and poison-related problems. DPI professionals and community pharmacists were invited to speak and sensitise the student pharmacists on the dynamic role of the DPI personnel.

\section{Limitation \& strengths}

This study was not limited to a single cohort of student pharmacists but included three groups, thereby avoiding the possibility of bias that can arise from the responses of a single cohort. This study is unique as it addresses students' perceptions of this rotation and remedial measures to improve their inclination towards this rotation. However, the collection of responses from students of a single university could be a limitation of this study. Also, the authors conducted only face validity of the questionnaire, a limitation which they hope to overcome in their extended studies.

\section{Conclusion}

Thus, experiential training in the DPI centre led to significant improvement in knowledge, attitude and perceptions of student pharmacists towards the DPI rotation. Locating appropriate information, responding to queries on time, and also understanding the role of the DPI pharmacists were the fundamental changes reflected in student pharmacists by the end of the rotation.

\section{Acknowledgment}

We acknowledge the help rendered by Mr. Nabeel Kashaan, Lecturer, College of Pharmacy, Jazan University, Miss Mosfirah Almalki, Miss Zhara Sayedi, Miss Mona Hassan, and Mrs. Jamila Hamzi, student pharmacists, Jazan University, for their assistance in data collection. 


\section{References}

Abou-Auda, H.S., (2008). Information-seeking behaviors and attitudes of physicians toward drug information centers in Saudi Arabia. Saudi Medical Journal, 29, 107-115

Ahmed Al-jedai, A., (2016). Pharmacy practice and the health care system in Saudi Arabia. Canadian Journal of Hospital Pharmacy, 69(3), 231-237. https://doi.org/10.4212/cihp.v69i3.1561

Alamri, S.A., Ali Al Jaizani, R., Naqvi, A.A., \& Ghamdi, M. (2017). Assessment of drug information service in public and private sector tertiary care hospitals in the Eastern Province of Saudi Arabia. Pharmacy (Basel, Switzerland), 5(3), 37. https://doi.org/ $\underline{10.3390 / \text { pharmacy5030037 }}$

Al Doughan, F.F., Alomi, Y.A., Iflaifel, M.H., (2019). Pharmacist's awareness and knowledge of reporting adverse drug reactions in Saudi Arabia. International Journal of Pharmacology and Clinical Sciences 8(1), 60-65. https://doi.org/10.5530/ijpcs.2019.8.11

Almazrou, D.A., Ali, S., Alzhrani, J.A., (2017). Assessment of queries received by the drug information center at King Saud Medical City. Journal of Pharmacy and Bioallied Sciences, 9(4), 246-250

Alomi, Y.A., AL-Mudaiheem, H., Alsharfa, A., Albassri, H., Alonizi, K., Alothaian, M., Alreshidi, M., Alzahrani, T., (2016). National drug information center services through Ministry of Health hotline calling center (937) in Saudi Arabia. Advances in Pharmacoepidemiology and Drug Safety, 5(1), 198

Asiri, Y.A., Al-Arifi, M.N., Al-Sultan, M.S., Gubara O.A., (2007). Evaluation of Drug and Poison Information Center in Saudi Arabia During the Period 2000-2002. Saudi Medical Journal, 28(4), 617-619

Batool, M., Muzzamil, U., \& Qureshi, R., (2019). Assessment and utilization of a pharmacist-assisted drug and poison information centre in Pakistan. International Journal of Medical Research \& Health Sciences, 8(4), 117-123

Cafege, A., (1989). The Pharmacist as a Source of Drug Information. Annals of Saudi Medicine, 9(3), 291-295. https://doi.org/10.5144/0256-4947.1989.291

Churi, S., Abraham, L., Ramesh, M., \& Narahari, M.G., (2013). Evaluation of poison information services provided by a new poison information center. Indian Journal of Pharmacology, 45(5), 496-501. https://doi.org/10.4103/0253-7613.117781

Gelayee, D.A., Mekonnen, G.B., Birarra, M.K., (2007). The needs and resources of drug information at community pharmacies in Gondar town, Northwest Ethiopia. BioMed Research International 2017, 1-6.

https://doi.org/10.1155/2017/8310636

Gharibyar, H., Sharif, Y., Al-Quasme, K., \& Fahmy, S., (2013). Physicians perception of drug information resources in the emirate of Abu Dhabi - UAE. Pharmacology \& Pharmacy, 4(1), 52-6. https://doi.org/10.4236/pp.2013.41007

Ghaibi, S., Ipema, H., \& Gabay, M., (2015). ASHP guidelines on the pharmacist's role in providing drug information. American Journal of Health-System Pharmacy, 72, 573-577. https://doi.org/10.2146/ sp150002

Hedegaard, U., \& Damkier, P., (2009). Problem-oriented drug information: Physicians' expectations and impact on clinical practice. European Journal of Clinical Pharmacology, 65, 515-522. https://doi.org/10.1007/s00228-008-0604-5
Khaliq, A., \& Sayed, S.A., (2016). Drug and poison information centres: An emergent need for health care professionals in Pakistan. Journal of Pakistan Medical Association, 66(6), 639-643

Omer, A.A.A., \& Abdularhim, M.E., (2017). The criteria of constructive feedback: The feedback that counts. J Health Specialties, 5(1), 45-48. https://doi.org/10.4103/2468-6360. $\underline{198798}$

Ponampalam, R., \& Anantharaman, V. (2003). The need for drug and poison information - The Singapore physicians' perspective. Singapore Medical Journal, 44(5), 231-242

Reppe, L.A., Spigset, O., \& Schjøtt, J., (2010). Which factors predict the time spent answering queries to a drug information centre? Pharmacy World and Science, 32, 799-804. https://doi.org/ 10.1007/s11096-010-9440-7

Rahmner, P.B., Eiermann, B., Korkmaz, S., Gustafsson, L.L., Gruvén, M., Maxwell, S., et al (2017). Physicians' reported needs of drug information at point of care in Sweden. British Journal of Clinical Pharmacology, 73(1), 115-125. https://doi.org/10.1111/j.13652125.2011.04058.x

Ruppelt, S.C., \& Vann, A.R. (2001). Marketing a hospital based drug information center (letter). American Journal of Health-System Pharmacists, 58(11), 1040. https://doi.org/10. 1093/ajhp/58.11.1040

Shankar, P.R., Mishra, P., Subish, P., \& Upadhyay, D.K. (2007). The drug information center at the Manipal teaching hospital-Going beyond drug information. Drug Information Journal, 41(6), 761-768. https://doi.org/10.1177/009286150704100608

Steel, N., Abdelhamid, A., Stokes, T., Edwards, H., Fleetcroft R., Howe A., \& Qureshi, N. (2014). A review of clinical practice guidelines found that they were often based on evidence of uncertain relevance to primary care patients. Journal of Clinical Epidemiology, 67(1), 1251-1257. https://doi.org/10.1016/ j.jclinepi.2014.05.020

Strobach, D., Gruber, A.C., Möhler, N.C. \& Vetter-Kerkhoff, C., \& (2015). Clinical impact of the hospital pharmacy drug information service: How does information on drug-drug interaction inquiries translate into clinical decisions? European Journal of Hospital Pharmacy, 22, 83-88. https://doi.org/10.1136/ejhpharm$\underline{\text { 2014-000487 }}$

Tefera, Y.G., Gebresillassie, B.M., Ayele, A.A., Belay, Y.B., \& Emiru, Y.K., (2019). The characteristics of drug information inquiries in an Ethiopian university hospital: A two-year observational study. Scientific Reports, 9, 13835 https://doi.org/10.1038/ s41598-019-50204-1

Verhoef, J.A.C., Miedema, H.S., Meeteren J.V., Stam, H.J., \& Marij E Roebroeck, M.E., (2013). A new intervention to improve work participation of young adults with physical disabilities: a feasibility study. Developmental Medicine \& Child Neurology, 55, 722-728. https://doi.org/10.1111/dmcn.12158

Walton, C.A., \& Knodel, L.C. (1983). Drug information centers: ASHP's role and effect of clinical pharmacy. American Journal of Hospital Pharmacists, 40(7), 1217-1218. https://doi.org/10.1093/ ajhp/40.7.1217

WHO [World Health Organisation]. (2004). WHO medicines strategy: Countries at the core, 2004-2007. Available at: https://apps.who.int/iris/bitstream/handle/10665/84307/WHO EDM 2004.5 eng.pdf;jsessionid=BB92924962B81A0BBB3497E9F 42C92CC?sequence $=1$ 
WHO [World Health Organisation]. (2020). International Programme on Chemical Safety - Guidelines for poison control. Available at: https://www.who.int/ipcs/publications/training poisons/guidelines_poison_control/en/index1.html

Wojas, A.W., \& Graham, A.S., (2009). Drug information services: The answer to your drug-related questions. American Family Physician, 80(7), 670-672

Wong, P-S.J., Ko, Y., \& Sklar, G.E., (2009). Identification and evaluation of pharmacists' commonly used drug information sources. Annals of Pharmacotherapy, 43(2), 347-352. https://doi. org/10.1345/aph.1L333 